\title{
Dealing with Renovations and Construction - for Optometry Tenants
}

Dale Willerton

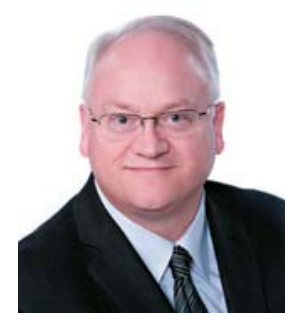

Jeff Grandfield

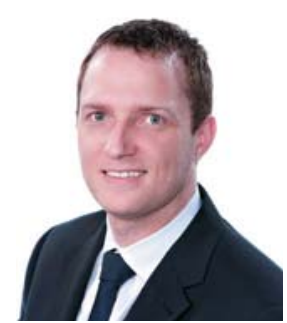

Dale Willerton and Jeff Grandfield - The Lease Coach are Commercial Lease Consultants who will work exclusively for tenants. Dale and Jeff are professional speakers and co-authors of Negotiating Commercial Leases Et Renewals FOR DUMMIES (Wiley, 2013). Got a leasing question? Need help with your new lease or renewal? Call 1-800-738-9202, e-mail DaleWillerton@TheLeaseCoach.com or visit www.TheLeaseCoach.com.

A $\mathrm{s}$ an existing optometry tenant, you might want or need cosmetic upgrades to your commercial property. Even if you are looking at new carpeting or a fresh coat of paint in your clinic, one of the best times to address these plans with your landlord is prior to your lease renewal due date. Your landlord may be willing to cover the costs of these repairs or upgrades to your clinic as a means to motivate you to renew your lease and remain in his property as a rent-paying tenant. If you are considering relocating your practice, you may have to deal with many more substantial renovations or construction.

As we explain in our book, Negotiating Commercial Leases \& Renewals FOR DUMMIES, there is more to consider and remember. Before completing any renovations or repairs to the property yourself, it's vital for optometry tenants to understand that landlords often reserve the right to pre-approve all design and construction to be done by the tenant for a couple of reasons:

- It's often the landlord's tenant allowance money being spent on those leasehold improvements. The landlord wants to ensure if at all possible that the improvements being made to the premises can live on and be used by the next tenant should you not stay for more than one lease term or your optometry business fails.

- It's the landlord's property and the landlord rightfully deserves to know whether your construction plans include penetrating a roof membrane or making other structural changes. If your design plans reveal that you'll be using a disproportionate amount of utilities, the landlord may also want some input on that (which is completely understandable).

Furthermore, in some cases, the landlord may include a review fee for looking at and approving the tenant's plans. This review fee may not appear in the offer to lease but may instead come to light in the formal lease documents. As with many other terms and conditions in this agreement, this fee is completely negotiable. With one client, we remember that the landlord was trying to charge the tenant $\$ 1,500$ to review their renovation plans ... The Lease Coach negotiated to eliminate this expense entirely as this was not a brand-new buildout and the plans were mostly cosmetic in nature.

We strongly advise that optometry tenants clarify the landlord's work to be done. The landlord's work, as listed in an offer to lease or formal lease renewal agreement, states very specifically any improvements that the landlord will do to the property - typically at the landlord's expense. One example can be the installation of a Heating, Ventilation, and Air-Conditioning (HVAC) unit on the property roof to provide warm and cool 
air inside. If the landlord is installing this for you, specify the unit's "capacity" (will it be sufficient to heat or cool your clinic?) and the "distribution" (the number and location of ducts inside your clinic). When it comes to HVAC systems and your lease renewal, you must consider the age of the unit, your history as a tenant (how long have you occupied the space?), and the person responsible for replacing the unit when the time comes. Many leases stipulate that HVAC replacement will be done at the tenant's cost; however, you can often negotiate for the landlord to replace the unit then or when it might fail in the future and to cover the expense as part of the lease renewal.

Optometry tenants may also choose to replace or upgrade their store flooring. In this case, the tenant should choose the preferred color and grade of flooring otherwise the landlord may simply install the cheapest and lowestquality flooring available as a cost-cutting measure. No matter what the upgrade or renovation project desired or planned, it is critical for the tenant to include as many details as possible to avoid future disagreements and unforeseen costs. Do not make assumptions on these details.

Any work that the landlord isn't doing will be stated as tenant's work. Typically, this work is at your expense with the approval of the landlord. The more extensive the lease deal and the buildout, the more likely the list of landlord and tenant's work is included in a separate exhibit attached to the offer to lease, formal lease agreement, and/or the renewal/amending agreement as the case may be.

Some landlords are casual about what leasehold improvements the tenant plans for the commercial space. With a fairly conventional type of business, the tenant's work list may be relatively short. In your case, however, you may have more extensive requests. Make sure that you include all plumbing, electrical, air distribution, lighting, partition walls, and even window coverings because they are fixed or attached to the window sill. Make sure that you're prepared to complete all of the tenant's work on your list, or your landlord may force you to do it later.

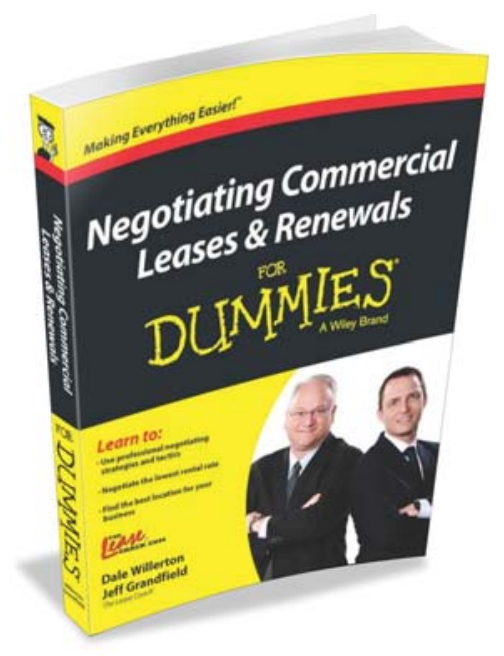

For a complimentary copy of our $C D$, Leasing Do's \& Don'ts for Commercial Tenants, please e-mail

JeffGrandfield@TheLeaseCoach.com. 